\title{
Wirkung des Zuckers auf die Zähne.
}

Heymann hat über die Einwirkung des Zuckers auf die Zahnsubstanz einige Versuche unternommen and gefunden, dass der Zucker an und für sich keine auflösende Kraft auf die Kalksalze des Zahnes ausübt, sondern nur die in einer wässerigen Lösung desselben unter gewissen Umständen sich bildende freie Säure vorzüglich Milchsäure. (Buchn. Repert. f. d. Pharm. 42. 3. 325.) B.

\section{Grüner Harn.}

Der von B raco n n ot untersuchte Harn war grün, ohne Sediment, roch wie frischer Harn, reagirte sauer. Auf $\mathrm{Zu}$ satz von wenig Kali verschwand die griune Farbe und liess sich dann durch Ansäuren des Harns nicht wieder herstellen. Dasselbe zeigte sich bei der Anwendung von überschüssigem Kalkwasser und Aetzammoniak, so wie beim Faulen des Harns; verdiinnte Säuren verwandelten die Farbe des Harns allmälig in eine rothe. Auch bei der Concentration verlor der Harn allmälig seine grüne Farbe und liess einen rothbraunen Rückstand. Der Verfasser glaubt, dass diese grüne Farbe von der Gegenwart von Cyanurin bedingt gewesen. (Journ. de Chim. méd. Nov. 1845.) $\mathrm{B}$.

\section{Schwefelblausäure im Katzenharn.}

La nderer sättigte das kohlensaures Ammoniak enthaltende Destillat von Katzenharn mit Phosphorsäure, dampfte ein und destillirte den Rückstand mit freier Phosphorsäure und Weingeist. Im Anfange ging eine Flüssigkeit über, die einen rettigähnlichen Geruch besass und durch Eisenoxydlösungen blutroth gefärbt wurde. Das später Uebergehende hatte jene Eigenschaft nicht. Jene Fluissigkeit gab am Sonnenlichte einen schwarzen Absatz und verlor dadurch dio Eigenschaft, durch Eisenoxydlösung geröthet zu werden. L a nderes vermuthet nach diesen Beobachtungen, dass im Katzenharn Schwefelblausäure vorhanden sei. (Buchn. Repert. XXXIX. - Pharm. Centrbl. 1846. No. 23.) B.

\section{Harustein zum Theil aus Blasenoxyd bestehend.}

Apotheker Schaffner in Meisenheim fand in einem nach der Section erhaltenen Harnsteine in 100 Theilen: 